\title{
The Triangle of Spiritual Intelligence, Metacognition and Consciousness
}

\author{
https://doi.org/10.3991/ijes.v8i1.12503
}

\author{
Athanasios Drigas ${ }^{(凶)}$, Eleni Mitsea \\ N.C.S.R. 'Demokritos', Athens, Greece \\ drait.demokritos.gr
}

\begin{abstract}
In the most challenging era in human history, the scientific community recognizes spirituality as a fundamental factor of human intelligence. Researchers from different fields such as Psychology, Medicine, Educational sciences, Economy and Business embrace the notion of Spiritual Intelligence. Nevertheless, it is considered as one of the most controversial and highly debated notions. The first section of this study gives a brief overview of the essential theoretical framework including definitions and theories related to Spiritual Intelligence. In the second section, we present a layered approach of Spiritual Intelligence based on the corresponding layered models of KnowledgeIntelligence-Consciousness. The results of this study showed that Spiritual Intelligence constitutes the backbone of every subsystem of human intelligence as it integrates, matures and transforms every physical, intellectual, and emotional ability and leads to the highest forms of self-awareness, self-knowledge and consciousness. The realization of our true Self, of our hidden and highest potentialities is tied inseparably with the hierarchical organization of knowledge through metacognition and executive functions. Specifically, higher order forms of self-observation, self-regulation through attentional, emotional and impulse control, problem solving, mental flexibility and adaptation could reveal our true and eternal identity. Spiritual intelligence is essential to be incorporated mainly into the dialogue of business ethics, leadership, mental health and psychotherapy, education especially in the case of learning disabilities and gifted education.
\end{abstract}

Keywords - Consciousness, self-awareness, metacognition, self-regulation, executive functions, neuroscience, perception, memory, attention, emotional control, problem-solving.

\section{Introduction}

The ordinary people employ 5-10 percent of their hidden potential. In recent years the scientific and technological breakthroughs, the life complexity and uncertainty urged scientific research towards the inexhaustible and scientifically unexplored spiritual tank that is common for every human being. For years spirituality as well as consciousness were unacceptable notions in most theories of intelligence. However new studies recognize the fundamental role of spirituality in the development of human intelligence. Multiple studies have shown that intelligence is not a static notion 
but a dynamic process supported by neuroplasticity [1]. According to Piaget's theory, the mind makes up a meaning-making system that employs structured mental operations to access increasingly complex and abstract aspects and relations in the world [2]. Drigas et al. [3] claim that the functioning of the whole cognitive mechanism depends on the development of the corresponding metacognitive mechanism that is hierarchically structured through self-organization and knowledge acquisition processes. According to Demetriou's cognitive development model (Demetriou, 2000; Demetriou \& Kazi, 2006 as cited in Adey et al., 2007), metacognitive abilities as well as executive control processes constitute the "hypercognitive system" that is essential to understand the special features of intelligence but also constitutes the building block of intelligence. [2]. In many eastern and western traditions it was assumed that the answers about knowledge and intelligence were hidden in spiritual "mysteries". Forerunners such as Maslow, Jung, Fowler, Rogers, Erickson mentioned in their psychological theories the role of spirituality in the development of human personality traits and motives. Subsequent studies represent spiritual intelligence as a superior and integrative form of intelligence, a blend of higher order personality characteristics, neurological processes, specialized cognitive abilities and spiritual qualities [4]. Wilber [5] advocates that spirituality involves stages of the highest developmental lines as well as spiritual experiences.

It is obvious that the concept of spiritual intelligence constitutes a challenging idea in the field of human intelligence but at the same time it raises fundamental and yet unanswered existential questions. In this study, we take into account the aforementioned theories and we try to adopt an as far as possible unifying approach. The central thesis of this article could be reduced as a paraphrase of Eistein's statement: In the middle of every multiplicity lies unity. In the middle of every intelligence lies consciousness. In other words, consciousness encompasses every aspect of intelligence. Consciousness is the cause of existence of intelligence. Every aspect of intelligence constitutes a reflection of consciousness. Spiritual intelligence integrates and transforms all the others and leads to the Upper-Level of Consciousness state [6]. The final objective of this study is to shed new light on intelligence through consciousness and spiritual intelligence as the missing link.

\section{Theory of Intelligence}

Undoubtedly intelligence is a multi-facet notion. It has been defined in many ways: as the capacity to think, to solve novel problems, to reason and to have knowledge of the world, the ability to structure our behavior [7], a cluster of cognitive abilities that leads to successful adaptation to a wide range of environments [8], the capacity to acquire skills [9]. Freeman (as cited in Sternberg) [9] defines it as sensory capacity, capacity for perceptual recognition, flexibility or association, imagination, span of attention, quickness or alertness in response. He adds the adjustment or adaptation of the individual to his total environment, the capacity to reorganize behavior patterns so as to act more effectively and more appropriately in novel situations, the ability to learn, to carry on abstract thinking, the effective use of concepts and symbols in deal- 
ing with a problem to be solved. Thurnstone holds the view that intelligence is the capacity to inhibit an instinctive adjustment [10]. Gardner defines it as a "biopsychological potential" affected by cultural and motivational factors [11].

Gardner in his Multiple Intelligences Theory proposed a new view of human intelligence. He states that individuals own at least eight intelligences, which are independent and can be genetically inherited, developed or improved through education and social environment. In his recently updated book [12] he defines intelligence as "a computational capacity to process a certain kind of information that originates from the human biology and human psychology. An intelligence entails the ability to solve problems or fashion products that are of consequence in a particular cultural setting or community". He introduces $8 \frac{1}{2}$ independent intelligences: musical, bodykinesthetic, logical-mathematical, linguistic, spatial, interpersonal, intrapersonal, naturalist, and existential as the half intelligence. Gardner chose not to include spiritual intelligence in his "intelligences" due to lack of scientific criteria. However, the discussion about spiritual intelligence has begun.

\subsection{Definitions of spiritual intelligence}

Emmons regards Spiritual Intelligence as a set of skills and abilities which are relevant to spirituality and they are used in an adaptive manner to solve problems related to meaning, higher-consciousness and transcendence [13-14]. According to Wolman [15], it involves higher-order abilities that lead to experiencing the seamless connection of everything and making conscious choices of personal spiritual strengths and limitations. Noble [16] describes SQ as a dynamic process, a continuous attempt to expand the borders, to be aware of the continuity when seeking the meaning in the wholeness rather than in its parts. Vaughan [17] suggests that SQ implies a capacity to see things from more than one perspective, to recognize the profound relationships between perception, belief, and behavior, to connect the personal to the transpersonal, to deepen awareness of our relationship to the transcendent. She states that SQ includes awareness of the body, mind, soul, and spirit that increases as consciousness evolves. Sisk [18] describes spiritual intelligence as a deep awareness of self in a mind-body-spirit Unity that connects us with the Universal Mind.

Zohar et al. [19] suggest that spiritual intelligence constitutes the ultimate intelligence which combines lower processes of rational and emotional intelligence in order to reframe, re-conceptualize and transform our experiences resulting in both higherorder cognitive processes arousal and consciousness revelation. Zohar supports that SQ gives us the ability to discriminate, to temper rigid rules with compassion, to deal with the existing limitations. Wigglesworth [20] emphasizes the ability to behave with compassion, equanimity and wisdom regardless of the circumstances. Amram and Dryer [21] emphasize on the human capability in controlling mind and action remaining pure in heart. King [22] defines SQ as a set of mental abilities, which contribute to the awareness, integration and adaptive application of the transcendent aspects of one's existence leading to a deep existential reflection, enhancement of meaning, recognition of a transcendent self, and mastery of spiritual states. Sinetar [23] defines 
it as inspired thinking, a creative talent that leads to an "early awakening", an early understanding of self.

\subsection{Theories building the foundation of spiritual intelligence}

Jung incorporated roots of spirituality into his theories. He was convinced that the spiritual life constituted the very root of psychic life. "The main task is to discover and fulfill our deep-innate potential, much as the caterpillar contains the potential to become butterfly". Self means becoming an homogeneous being, a totality of balanced spiritual and psychological forces, or in other word an "individuality" (jung, 1959 as cited in Haynes, 2016) [57]. He thought that the journey of transformation coincide with the journey to meet the Self through spiritual experiences. Comparing the emergence of the ego from the unconscious with the emergence of the Demiurge, he develops his theory about the archetype of the Self. Jung approaches the term self in different senses; the third and most important reference presents Self as an integrating or transforming aspect of personality. Self-transformation occurs when the Self archetype through its transcendental functions synthesizes the opposites in the personality. Furthermore, Jung uses 'mandala' as a sacred geometrical representation of the central Self. He used 'mandalas' with his patients to help them listen to their inner voice, to decentralize ego, to break the murmuring of obsessive thoughts, so that they could discover new routes of liberation and to come to new states of consciousness. Among Jung's four functions of consciousness, feeling and intuition are mostly related with SQ. Another Jung's theory, the theory of synchronicity supports the idea that there is always a meaningful connection between the 'subjective' inner psychic condition and the 'objective' external events [24-25].

Dabrovski's theory of positive disintegration [26] contributed to the concept of spiritual intelligence. In one part of the theory, over excitabilities comprise a heightened physiological experience of stimuli resulting from increased neuronal sensitivities. He identified five forms (psychomotor, sensual, emotional, imaginational and intellectual) that enable one to manifest an unusual capacity to care, an insatiable love of learning, a vivid imagination and endless energy [27]. In the other part, individual development is a process of lower cognitive and emotional structures being disintegrated and replaced by higher. Particularly in the last two levels of development, individuals are able to compassionate, to live in service of humanity, to operate with spiritual concerns, to resolve inner conflicts, to seek harmony. Obviously, Dabrovski's model represents the core behaviors of spiritual intelligence [18].

Rogers [28] person-centered theory gives prominence to the fundamental element of 'actualizing tendency', a term describing an inherent tendency within ourselves to grow and reach our full potential. Self-actualization is the ongoing process of maintaining and enhancing the individual's self-concept through reflection, reinterpretation of experience. Individuals aim to incorporate in the same way the "real self" and the "ideal self", thereby cultivating the appearance of the fully functioning person" [29]. Self-actualization, according to Maslow's theory is the coincidence of the positive qualities of self-awareness, the realization of personal potential, self-fulfillment, pursuing personal development and peak experiences [30]. Maslow described human 
development through a hierarchy of basic needs all leading towards Self - actualization and "Transcendence". In the level of Transcendence, one helps others to selfactualize, to find self-fulfillment and realize their potential. Transcendence involves intuition, an increased sense of meaning, relevance to others and to the world, exchange of wisdom, finding spiritual significance in life.

According to Vaughan [17] spiritual intelligence depends on familiarity with at least three modes of knowing (sensory, rational, and contemplative) as well as of multiple levels of consciousness. Influenced by Wilbers's ideas [31], she adds that the capacity of distinguishing truth from illusions relies on the constant access to pure awareness that we are conscious of all levels of consciousness that spirit pervades and unifies every state of consciousness. Consciousness expansion is associated with practices that quiet the mind and refine perpetual sensitivity to energy, beauty, sound, light. She is convinced that everyone has the potential of developing spiritual intelligence, just as everyone has a capacity for intuition, thinking, sensing, and feeling [32]. The emergence of the growth potential occurs through spiritual maturity that implies a depth and breadth of vision. Vaughan underlines the role of attention in raising self-awareness and becoming spiritual mature. Attention can be voluntarily directed inwards and quiet the mind even for a minute from inner distractions such as past thoughts, future plans, personal stories. Attention could cultivate awareness, emerge the process of undoing old habits smoothing the way for spiritual paths leading gradually to spiritual maturity and higher states of consciousness. Wishing to depict stages on the spiritual path, she invokes Christianity, Sufism and Zen Buddhism, Taoism. The concern is expanded from the Self to the well-being of the group, from the self-awareness to extend compassionate concern to all beings. Vaughan draws a parallel between the spiritual maturity progress and Fowler's [33] six stages of faith. The spiritual quest of meaning lies in silence in which boundless compassion arises and learning with wisdom fit together hand-in-glove.

King and DeCicco [34] proposed four core components:

1. Critical Existential Thinking: This principle involves the cognitive ability to think critically and to integrate scientific knowledge to personal experiences in order to come to original conclusions or personal philosophies about existential issues.

2. Personal Meaning Production: The ability to transform physical and mental experiences in a meaningful life purpose through cognitive and emotional processes such as symbolization and integrative organization [35].

3. Transcendental Awareness: The ongoing awareness of an transcendent Self, an inner knowing, a waking state of consciousness. Self-realization as cognitive and metacognitive processes outcome could be achieved through depth and holistic perception as well as self-awareness and reflection [36].

4. Conscious State Expansion: The ability to enter and exit higher states of consciousness (pure, cosmic, unitive consciousness).According to Maslow [37] expanded or altered states of consciousness are deeply rooted aspects of spirituality and the most important, they are to some extent under our control. Equally im- 
portant, research has demonstrated differences in brain functions between all states of consciousness, including those with spiritual character [38].

Amram [39] was the first author in developing the ecumenical grounded SI theory based on interviews among people regarded as spiritual intelligent. Initially, he identified seven major themes and subthemes of SQ, which were almost universal across participants. In a subsequent collaborative research [40] the model was re-classified into the following five inter-related domains:

1. Consciousness

2. Grace

3. Meaning

4. Transcendence

5. Truth

Specifically, Intuition, Mindfulness and Synthesis consist the capabilities with which we are able to raise awareness and self-knowledge so as to experience higher levels of consciousness. Grace reflects Inner-Directedness ingrained in Discernment and Freedom, Inspiration, Gratitude, Joy inherent in each present moment. Meaning is a trait of the ability to "experiencing significance in daily activities through a sense of Purpose and a call for Service, including in the face of pain and suffering". Transcendence represents the transition from the separate egoic self into an interrelated wholeness. Truth presupposes to live in open acceptance, forgiveness, love for the creation, self-denial.

Wigglesworth [20] determined 21 skills in four categories, which reflect the move towards less ego and greater expansion of awareness. These include:

1. Higher self/ego self-awareness

2. Universal awareness

3. Higher self/ego mastery

4. Social mastery/ spiritual presence.

Higher self-awareness springs from the awareness of our worldview, life purpose, hierarchy of values, complexity of inner thoughts. Universal awareness indicates the absolute consciousness, the experience of transcendent oneness, the awareness of interconnectedness of all life, breadth of time/space perception. Higher self mastery keeps us in an on ongoing spiritual growth through faith and guidance from spirit. Spiritual presence indicates a spiritual teacher/mentor, a gentle energy who makes compassionate and wise decisions.

\section{A Layered Approach of Spiritual Intelligence}

In this study, we present a layered approach of spiritual intelligence integrating the most fundamental elements of the aforementioned theories in the models of Knowledge-Intelligence-Consciousness and in the layered model of human consciousness $[3,6]$. We opted to utilize a telecommunication and computer networks 
model because it comprises a multi-layered structure that takes into account theories of cognitive science, psychology, philosophy and Information Technologies. According to the model, every aspect of intelligence unfolds as knowledge being organized and transformed through metacognition in hierarchically superior levels of consciousness. Consequently, intelligence coincides with the levels of self-organization or in other words with the levels of metacognitive development we have achieved. In our presentation, we reduced our analysis in two sections: the primary and the higher order consciousness level.

\subsection{The primary consciousness levels of spiritual intelligence: Physical, Intellectual, Emotional}

The physical level refers to our ability to "see a world in a grain of sand" (William Blake, Auguries of Innocence), to recognize the underlying structures of our sensations. It is our faculty of perception, the awareness of the external and internal phenomena, our higher ability to filter unwanted stimuli, to direct attention in order to collect facts and synthesize data [3]. Moreover, the organization of external world raises questions about the meaning of life, death, suffering [41]. It correlates with our body awareness and skillful use [42], the ability to listen to our body's voice, to translate our emotions into simple movements [43], the body-mind connection and integration, the wisdom that comes from within. Isaacs describes it as the poetry in motion and associates it with the ability to engage the will and develop emotional fluency, control, centering and patience. By training the body and adopting healthy lifestyles, we strengthen new neuron pathways that can help us break out of our box, to be connected with our spirit, to experience the wholeness. Mindfulness meditation training techniques have been proven that foster resilience, cognitive and emotional regulation as well as self-consciousness [44]. Saotome [45] underlines that the mind exists in every cell of our bodies as well as every thought, every emotion. According to Maslow's Hierarchy of Needs, if physical abilities are not in place, attempts to develop all the other abilities will be stunned [42].

The intellectual level is more relevant with the transformation of information to Knowledge. It is associated with the left hemisphere, the hemisphere of separateness that makes us single solid individuals and connects us with the external world [46]. It allows us to analyze, categorize, organize and associate information, to uncover relations between concepts, draw connections between objects and events, to extrapolate beyond the information given. It is a pool of mental energy [47], a set of cognitive abilities, such as reasoning, abstract thinking, problem solving, planning governed by learning "algorithms", emotions and cognitive functions like attention and memory. Drigas et al. approach intelligence as the outcome of knowledge acquisition improvement through mental self-observation and control [3]. He also highlights that the aforementioned process could lead us to a higher state of self-organization, awareness and consciousness.

The emotional level corresponds to our ability to discriminate and be creative, to perceive access and generate emotions, to assist thought, to understand emotions and emotional knowledge, to reflectively regulate emotions promoting emotional and 
intellectual health [48]. Goleman et al. [49] highlighted five emotional clusters: Selfawareness, Self-regulation, Motivation, Empathy and Social Skills. Drigas et al. [50] recognized into the aforementioned components, the role of cognitive and metacognitive processes in emotional intelligence's development. Thus, a new-layered model of EI was developed which is in tune with the pyramid of functions of general intelligence [3] and supports the idea that emotions are reflections of our consciousness states. According to Amram and Dryer [21] EI involves a set of abilities that draws on spiritual resources. According to Fuller [51] the emotion of wonder responds to unexpected features of the environment and fosters receptivity, openness, metaphysical thinking and moral sensitivity.

\subsection{Higher order consciousness levels: Self-actualization, transcendence and unity}

Spiritual intelligence aspires to fulfill the innate and ultimate potentialities that all human beings have the tendency to develop. In Maslow's theory [30], selfactualization constitutes an ongoing process of becoming fully functioning people, a motivation for growth of ultimate capacities. Specifically, self- actualizers manifest:

- Efficient perceptions of reality: They are able to detect the fake and the dishonest in personality, to judge people correctly. Furthermore, they see concealed or confused realities, they accept the unknown, and they live closer in the real world of nature rather than in the man-made mass. They excel due to their capacity to reason, to perceive the truth, to come to conclusions, to be logical and to be cognitively efficient.

- Comfortable acceptance of self, others and nature: Individuals accept themselves and their own nature in the stoic style with all its discrepancies from the ideal image. Those self-actualizing people observe the world with wide, uncritical, undemanding and innocent eyes, and they accept the others without defensiveness.

- Spontaneity; Simplicity; Naturalness: Self-actualizers behave with spontaneity, simplicity, autonomy and naturalness. Even if they behave in an unconventional manner, this is not superficial but essential or internal. Furthermore, they obey their codes of ethics discarding ordinary accepted hypocrisies, lies and inconsistencies of social life. The aforementioned attitudes imply superior self-awareness and qualitatively different motivational life.

- Problem centering: In this case, they feel that they have a mission or responsibility in life. They are concerned about eternal questions that try to answer within a framework of values that are broad and universal permitting them a wider breadth of vision.

- The quality of detachment: The Need for Privacy: They are able to remain undisturbed by what produces turmoil in others, because they are more objective, less ego-centered and their intense concentration produces such phenomena as absentmindedness. 
- Autonomy; Independence of Culture and Environment; Will; Active Agents: The honors, the status, the rewards, and the prestige have become less important than self-development and inner growth.

- Continued freshness of appreciation: Self-actualizers have the capacity to appreciate endlessly the basic goods of life with awe, pleasure, wonder even ecstacy.

- Peak experiences: "Peakers" seem to live in the realm of being, experiencing the deep meaning, and the ecstatic beauty.

- Gemeinschaftsgefühl: They have a deep feeling of identification, sympathy and affection, a genuine desire to help human race. However far apart they are from the others, they nevertheless feel an underlying kinship with these creatures whom they must regard with.

- Interpersonal relations: They are compassionate with all mankind. Nevertheless, they show high evaluation and speak realistically and even harshly of those who deserve it. They prefer more profound interpersonal relations and are socially equipped.

- Democratic character structure: The give a certain quantum of respect to any human being, they learn from everybody, they are not aware of differences of class, education, race and color.

- Discrimination between Means and Ends: These individuals are strongly ethical, determine the notions of right and wrong in an unconventional way and they are fixed on ends rather than means.

- Unhostile sense of humor: They do not laugh at hostile, superiority or authorityrebellion humor. In contrast, they prefer jokes that have something to say.

- Creativeness: Creativeness constitutes a potentiality given to all humans. Less encultured (namely less inhibited, less constricted, less bound) individuals develop creativeness through a healthy and humble personality whatever they do.

- Resistance to enculturation: They get along with the culture in various way, but in a certain profound and meaningful sense they resist enculturation and conventionality.

Rogers [52] discussed the fully functioning person as the one who lives with an active actualizing tendency, the main motivational force in all human beings. According to the Rogerian approach the key for self-actualization is located in self-regard. Selfactualizers deal with the society pressures that lead individuals to a struggle between their Real Self (the self that they are capable of being and willing to be) and the Ideal Self (the self that the society imposes). Self-actualizing individuals cope with selfincongruities, as they are able to control their defence strategies and adopt adaptive coping mechanisms. A fully functioning person is described by five characteristics:

a) Openness to experience

b) Existential living

c) Organismic trusting

d) Experiential freedom

e) Creativity 
Ken Wilber [53] points out that Transcendence or super consciousness constitutes an inevitable effect of the evolution of remembrance, a mode of self-becoming merely component of a higher-order self. Specifically, in this process what is

a) Whole becomes part

b) What is identification becomes detachment

c) What is context becomes content

d) What is ground becomes figure

e) What is subjective becomes objective

f) What is condition becomes element. The bliss of transcendence arises from giving way to Ananda and mahasukha, the supreme bliss, euphoria of no longer being ego.

Transpersonal Psychology is concerned about the development of humanity's highest potentialities through transcendental states of consciousness. Daniel's [54] interpretating Lajoie's et al. [55] study, supports the idea that there is a "spiritual" reality that "transcends" our ordinary consciousness while humanity's "highest potential" is to achieve unity with this transcendental reality. Walsh and Vaughan [56] associate transcendence with experiences in which "the sense of identity or self extends beyond the individual or personal to encompass wider aspects of humankind, life, psyche or cosmos".

Thomas Merton (as cited in Haynes, 2016) [57], claimed that self-transcendence is the doorway from the false (i.e. illusory, non-spiritual) to the true self (spiritual, contemplative and enlightened). The egocentric self is concerned with needs, superficial identity and includes thoughts, emotions, personas, roles. Frankl [58] supported the idea that self-transcendence is associated with the potential meaning of life and he recognized three levels in order to overcome the "existential vacuum" and to develop a free and responsible human spirit:

a) Seeking ultimate meaning

b) Seeking situational meaning

c) Seeking one's calling without meaning humanity is ontologically bankrupt. Spirituality implies transcendence, which is the pathway to the true self and consequently the essence of existence.

Piedmont [59] describes it as a fundamental capacity that enables us to sense a synchronicity to life and to develop a bond with humanity. Cloninger et al (as cited in Romeu et al., 2015) [60] considered self-transcendence as a measurable personality trait that identifies the self as an integral part of the whole universe. Levenson et al. (as cited in Romeu et al., 2015)[60] conceptualize it as a key component of wisdom that derives from aging and development in lifespan.

According to the authorities of Advaita Vedanta and Samkhya, if consciousness is our true identity or "Self", we have to cease identifying with the occurrences of the body-mind and to live as consciousness, by means of constant self-transcendence [61]. 
Maslow placed self-transcendence a motivational step beyond self-actualization. According to his definition "Transcendence refers to the very highest and most inclusive or holistic levels of human consciousness, behaving and relating, as ends rather as means, to oneself, to significant others, to human being in general, to other species, to nature and to the cosmos" (as cited in Daniels, 2001) [54]. The innate force of selftranscendence leads persons in seeking something beyond personal benefit. Transcenders strive for the furtherance of some greater cause, the service to others, the sense of a purpose of life, the expansion of identification beyond the personal ego [62]. Maslow listed 24 characteristics described briefly below [30].

Transcenders envision profound states of flow, known as "peak experiences", during which they are consciously aware of their human potential and they feel alive in a world that overflows with inexpressible truth and beauty. Longer lasting periods of cognitive blissfulness correspond with superior spiritual experiences known as "plateau experiences". They speak the language of being and they perceive unity, under the aspect of eternity, in all things at the same time. Transcenders recognize each other even upon the first meeting and they come to almost instant intimacy and mutual understanding.

Transcenders, as more holistic, have the natural tendency to synergy that transcends the dichotomy between selfishness and unselfishness. Obviously, there is easier transcendence of the ego, the self, and the identity. Transcendent experiences and illuminations bring clearer vision leading them possibly to discoveries and innovations. According to Maslow's impression, they can be more ecstatic, but they pay the price experiencing a cosmic sadness when recognizing the blindness, the cruelty and the shortsightedness. The knowledge does not annul the attractiveness of mystery. The more they know, the more they become passionate feeling the smallness, the ultimate ignorance. They are "reconciled with evil" as they understand its occasional inevitability and necessity in the larger holistic sense.

Walsh and Vaughan [63] claim that transcendence refers to the expansion of our consciousness through techniques as a part of an "art" that integrates the contemplative core of the world's great religious traditions. This technology consists of six essential and interdependent elements, qualities or processes that aim to purify humans from attentional instability, distorted emotions and scattered desires.

- Ethics: Ethical behavior, as a natural expression of identification, redeems us from greed and anger and cultivates kindness, compassion, and calm.

- Attentional training: Attentional control in combination with training other fundamental mental processes such as memory and perception help the untrained mind to monitor and regulate emotions, moods, motivations behaviors and actions. We could overcome the fickle wanderlust by maintaining a vigilance state, being focused for a prolonged period, and being able to bring back a wandering attention. [64].

- Emotional transformation: Firstly, we should to be aware of our destructive emotions, such as fear, anger and regulate them consciously and appropriately. Secondly, we should be able to channel the negative emotions in order to enhance the equivalent positive emotions. Thirdly, cultivation of equanimity fosters emotions 
to remain unconditional and unwavering in a state that could be compared with what Stoics called "apatheia".

- Motivation: Transcenders should be able to control their desires as well as the concomitant impulsivity in order to achieve the motivational shift from egocentric to allocentric (concern for others) [65].

- Refining awareness: Mind's natural tendency to roam through the past and the future could be compared with what Plato described in his allegory of the cave. Illusions are the chains that imprison us. Only when we keep attention in the present moment, we are able to perceive the true form of reality through the opening of an inner eye, known in ancient Greek philosophy as "nous".

- Wisdom: Transcenders are transformed developing direct insight into the nature of mind, self, consciousness and cosmos.

Spiritual intelligence enlivens full humans' potentialities in the final level of Unity. Two interdependent paths of human evolution or consciousness are available to all human: growing up and waking up. The process of development through the structure stages is growing up and usually called personality development or spiritual intelligence in western psychology. The spiritual experience, what one has on the statestages, is called waking up and known by the spiritual traditions as the pathway to true enlightenment. Wilber [66] maintains that each path seems independent but an integral approach has to have at least these two major factors of human development included. With spiritual intelligence, we think that we are one with all, with spiritual experience we are one with all in a state of consciousness called kosmic consciousness or ultimate non-dual unity consciousness.

Biela [67] recognized unity as psychological reality, as a self-integrating process that leads to the person's internal unity, the true self-unity. The main idea is that human beings are intending to build gradually the unity with themselves, with other people, with natural environment and finally to build the unity with the transcendental reality. Empathic abilities and cognitive goals are the most important components of the model. According to Biela, human communities, which reach better unity-doing skills, are in a better position to survive in evolutionary process.

According to Plotinus and Advaita thinkers, full reality of the Self is brought to oneself in a mystical awakening constituted in a mystical non-dual awareness. Non duality constitutes the foundation of knowledge and can be known only as immediate presence and awareness that transcends the subject-object duality. Union makes up the encompassing consciousness, the status of the self that has ascended to the One, our eternal identity, the power of recognition that is involved in all forms of knowledge. According to Plotinus, the ultimate reality, the ultimate explanation originates from the void replete called oneness, the pure consciousness that exists prior to the act of being conscious of anything [68]. The one could be considered as the "actualization" of cognition, in other words metacognition.

Homer's and Hesiod's traditional mythological explanations of the world stressed the rational unity of things. Pre-socratic philosophers were strongly influenced by the older cosmogony, according to which the world originated from an undifferentiated or amorphous unity. For Heraclitus complete unity was found on Logos, which is com- 
mon, permanent and unchanging and leads to the true knowledge. For Thales everything in the material world was some form of water- this for him was the result of a search for some kind of all-embracing unity. Parmenides claims that universe is a singular, unchanging and undivided unity. Empedocles described the Globe (Sphaera) as a prototype stereoscopic image of the unity and harmony, of the completeness and self-sufficiency, according to Orphic concept of friendly collaboration of all ingredients, which are connected together with the strong links of Love, composing the "One". Pythagoras believed that man is obliged to understand his existence through the universe he finds himself in order to experience an integral unity, harmony and completeness. Atomists such as Democritus acknowledged the unity amongst different elements [69-70].

\section{Spiritual Intelligence-Metacognition-Consciousness}

According to Kiaei [71], metacognition is able to explain every action or behavior that involves intentional or conscious cognitive processes. In the case of the spiritual intelligence, metacognition is essential in order to recognize self-actualizing needs and goals as well as facilitate the regulation of personal efforts towards these goals. For instance, metacognition can contribute to the relaxation of unjustified defence mechanisms or to the employment of more adaptive defence styles. Reflection and awareness constitute fundamental metacognitive abilities that foster our intrinsic goals and develop a sense of meaning in life (Ryan \& Deci as cited in Kiaei, 2014).

Both metacognition and spiritual intelligence aim to actualize our potential in order to expand our self-consciousness, the awareness of our own existence including psychological elements such as self-perception, self-experience and self-control. Metacognition could help us to learn from our experiences, to get aware of our thoughts, to have a clear concept of our real identity, which is the utmost requirement of a reflective mind. A reflective mind enables an individual to regulate his or her emotions, to have empathy or compassion for others, to handle conflicts. Unhappiness and frustration are due to lack of self-awareness and unrealized spiritual potential. [72].

Singh et al. [72] suggest that metacognition meditation could create and reorganize neural pathways improving brain plasticity. Awareness, self-regulation and refocusing could develop our self-control skills including attention, stress management, impulse control. Vago et al. [73] investigates the role of mindfulness in developing selfawareness, self-regulation and self-transcedence through neuropsychological processes. It was found that S-ART is associated with perceptual, meta-cognitive, emotional and behavioral processes such as motivation, attentional and emotional regulation. Drigas et al. [44] emphasize that mindfulness constitutes not only a training technique but also a metacognitive ability related to self-leadership, cognitive flexibility, cognitive inhibition, problem solving and most important the attentional control.

Santoso [74] investigated the interrelationship between spiritual intelligence metacognition and whole brain learning in english writing. The processes of laterality (balance between the right and the left side of the body), centering and focus im- 
proved positive emotions, memory, association processes, sense of self, interaction, conscious reasoning, motivation as well as spiritual intelligence.

Attention and memory play a fundamental role on spiritual development. Without memory and attention, we are not able to monitor, control, and transform anything. Newberg, a radiologist observed the brains of Tibetan, Buddhists, and Franciscan nuns when engaged in deep prayer or meditation. It was found that the activity in frontal area -the attention area of the brain- was increased. According to Selman et al. both spiritual intelligence and consciousness depends on Gamma rythm (super-fast (40) Hz oscillations) that emerges the whole brain. Furthermore, the temporal lobes, the limbic system, the amygdale and the hippocampus collaborate in order to regulate emotions and record experiences into deep memory [75].

Drigas et al. [6] presented a layered model of human consciousness based on a person's cognitive and metacognitive profile with special emphasis on humans' growing difficulty to reach a higher-order consciousness state. Each level requires ever more higher cognitive and metacognitive abilities that sculpt higher spiritual characteristics. However, higher forms of consciousness are associated with higher order beliefs, meaning in life, ultimate purposes, vision, inspiration, self-sacrifice, transcendence of self-focused needs, interaction with natural forces and deep absorption. The ultimate level of consciousness, the Unity consciousness coincides with self-luminosity that is the realization of our true nature.

According to Tart [76] "what we can know depends on the state of consciousness we are in. If we do not enter that state and work appropriately with it, we will never know the answers. In our times, we have forgotten about the state specificity of knowledge in regard to many vital spiritual questions. Thus we approach them only from an ordinary state and get answers that are distorted reflections of reality".

Wilber [77] described consciousness as a twofold structure: the deep and the surface. Deep structure represents potentials and limitations, while surface a particular manifestation of the deep structure. Consciousness evolution depends on the hierarchical transformation of the deep structure within new surface structures unfold or operate. All deep structures emerge when remembered in the platonic sense of anamnesis while surface structures emerge when being taught. Everyone inherits the same deep structures but everybody learns individual surface structures dissimilarly.

Brazdau [78] examined the validity of a list of traits, skills and abilities that describe the conscious experience under the construction of the consciousness quotient. The structure embodied factors such as physical, emotional, cognitive, social, self, inner growth and spiritual. The results showed that consciousness is related with "witnessing awareness", a type of subjective non-dual experience, a spiritual enlightenment, awakening or spiritual revelation that transcends the cognitive observer, the self and the mind.

Ahuja used Brazdau's consciousness quotient inventory [79] with the aim to determine the intercorrelations among physical, mental, emotional, social, spiritual and self-consciousness. The strongest correlation was found on spiritual and selfconsciousness. She concluded that self-consciousness constitutes the lower power end and spiritual consciousness the higher end that emerges due to self-awareness. 
Kuhl et al. [80] postulated that personality draws on two modes of information processing: the "explicit self-regulation system" and the "implicit" self-regulation system". The latter deals with conscious and unconscious self-related processes using "implicit" memory. Well-developed implicit self-regulative competencies play an important role for intrinsic motivation, subjective experiences of ego transcendence and are closely linked with spirituality.

Adams [81] supports the idea that consciousness evolves through the simultaneous awareness of body, emotions, spirit and mind. Specifically, she claims that within the physical domain, individuals should be "present" in the physical self, understanding the role of body's energy, chemistry and interconnectedness with the physical universe. "Presence" in the emotional domain is associated with depth of relationships, connection with deep feelings, plasticity to manage with many kinds of people and situations, less repressed or extensive defence mechanisms. In mental domain, individuals are able to be flexible, to recognize the interconnectedness of ideas and of all life, to discriminate, interpret and draw conclusions, to see larger patterns and grasp the "whole" picture. In the spiritual domain, awareness is enhanced through internal experiences, self-reflection, silence, inner interconnectedness, values, meaning and purpose an individual creates for his or her self.

Vedantic schools considered mind and body as the underlying unitary reality described as "soul", "atman" or "Brahman". Consciousness is explained in the singular as the only reality and is characterized as pervasive, omnipresent and omniscient. The truth is revealed by intuitive research by diving deep into the self in the process of absorption. According to Upanishads' non-duality approach (Adwaitha), the outer world constitutes an extension of "self". Only consciousness exists and the world as we see is a projection of the unitary consciousness. The individualized consciousness constitutes a perceptual error due to ignorance, attachment to objects by way of desire or aversion. Moreover, it is fearful of losing its existence and desire to cling to life. Thus, the true nature of self as universal consciousness is forgotten. Getting rid of this ignorance leads to liberation. Upanishads state that the highest state of existence called "Thuriya" is a superconscious state in which there is no duality [82]. The very nature of this universe is sat (absolute existence)- cit (pure consciousness)- ananda (bliss). Supreme knowledge is the ground out of which the diversity of knowledge and experience grows [83].

\section{Conclusion}

In search of Spiritual Intelligence, we approached it in a holistic way, as integrative intelligence, an open-ended field, the pathway where all human abilities (physical, intellectual or emotional) as well as qualities (values) are crossed. In this pathway we are able to discriminate our deepest motives from the false ones, our eternal identity from the illusion of the ego, our common destination from cultural discriminations, the unapproachable truth that exists behind the personal and distorted realities. According to Wilber [77] a person's growth from infancy to adulthood is a microcosmic reflection of universal growth and has the same soul: the unfolding of ever higher- 
order unities and integrations. This study proposes a layered approach with the aim of representing the increasing physical, intellectual, emotional and spiritual efforts that are required in order experience the revelation of consciousness. Metacognition constitutes the vector of consciousness, the "genetic" code of intelligence, the adjunction between the objective world of cognition and the subjective of spiritual experience.

Developing spiritual intelligence we could give purpose, direction and meaning to our chaotic, hyperactive Century, where all dimensions -technology, family, culture, business, leadership, values, and education are in radical change simultaneously [75]. Spiritual intelligence could enhance every aspect of life: physical and mental health, work and life satisfaction, ethical business, successful leadership, holistic human resource development, democracy, general and special education. Specifically, we should emphasize the role of spiritual intelligence on learning even from the early years in order to promote the future leaders, peacemakers and innovators.

Considering all these, we could bring our study to a close paraphrasing T.S Elliot's words: Spiritual intelligence is the pathway to the knowledge we have lost in information, to the wisdom we have lost in knowledge, to the life we have lost in living.

\section{$6 \quad$ References}

[1] Drigas, A. S., Karyotaki, M., \& Skianis, C. (2018). An Integrated Approach to Neurodevelopment, Neuroplasticity and Cognitive Improvement. International Journal of Recent Contributions from Engineering, Science \& IT (iJES), 6(3), 4-18. https://doi.org/10. 3991/ijes.v6i3.9034

[2] Adey, P., Csapó, B., Demetriou, A., Hautamäki, J., \& Shayer, M. (2007). Can we be intelligent about intelligence? Why education needs the concept of plastic general ability. Educational Research Review, 2(2), 75-97. https://doi.org/10.1016/j.edurev.2007.05.001

[3] Drigas, A. S., \& Pappas, M. A. (2017). The Consciousness-Intelligence-Knowledge Pyramid: An 8x8 Layer Model. International Journal of Recent Contributions from Engineering, Science \& IT (iJES), 5(3), 14-25. https://doi.org/10.3991/ijes.v5i3.7680

[4] Hosseini, M., Elias, H., Krauss, S. E., \& Aishah, S. (2010). A review study on spiritual intelligence, adolescence and spiritual intelligence, factors that may contribute to individual differences in spiritual intelligence, and the related theories. International Journal of Psychological Studies, 2(2), 179.

[5] Wilber, K. (1999). An approach to integral psychology. The Journal of Transpersonal Psychology, 31(2), 109.

[6] Drigas, A. S., \& Karyotaki, M. (2019). A Layered Model of Human Consciousness. International Journal of Recent Contributions from Engineering, Science \& IT (iJES), 7(3), 4150. https://doi.org/10.3991/ijes.v7i3.11117

[7] Legg, S., \& Hutter, M. (2007). A collection of definitions of intelligence. Frontiers in Artificial Intelligence and applications, 157, 17.

[8] D. K. Simonton. An interview with Dr. Simonton. In J. A. Plucker, editor, Human intelligence: Historical influences, current controversies, teaching resources. http://www.india na.edu/ intell, 2003.

[9] Sternberg, R. J. (Ed.). (2000). Handbook of intelligence. Cambridge University Press.

[10] Thurstone, L. L. (1924). 1973. The nature of intelligence. London: Routledge. 
[11] Gardner, H. (1993). Frames of Mind-the theory of multiple intelligences Fontana. Gardner, W. and Abu Libde, A. (1995). Professional development schools: How well do they travel, 303-315.

[12] Gardner, H. (2006). Multiple intelligences: New Horizons. New York: Basic Books

[13] Emmons, R. A. (2000). Is spirituality an intelligence? Motivation, cognition, and the psychology of ultimate concern. The International Journal for the psychology of Religion, 10(1), 3-26. https://doi.org/10.1207/s15327582ijpr1001_2

[14] Amram, Y., \& Dryer, C. (2008, August). The integrated spiritual intelligence scale (ISIS): Development and preliminary validation. In 116th annual conference of the American Psychological Association, Boston, MA (pp. 14-17). https://doi.org/10.1037/e520652012-002

[15] Wolman, R. (2001). Thinking with your soul: Spiritual intelligence and why it matters. New York: Harmony

[16] Noble, K. D. (2001). Riding the windhorse: Spiritual intelligence and the growth of the self. Hampton Press.

[17] Vaughan, F. (2002). What is spiritual intelligence? Journal of humanistic psychology, 42(2), 16-33.

[18] Sisk, D. (2002). Spiritual intelligence: The tenth intelligence that integrates all other intelligences. Gifted Education International, 16(3), 208-213. https://doi.org/10.1177/0 26142940201600304

[19] Zohar, D., Marshall, I., \& Marshall, I. N. (2000). SQ: Connecting with our spiritual intelligence. Bloomsbury Publishing USA.

[20] Wigglesworth, Cindy (2006) "Why Spiritual Intelligence is Essential to Mature Leadership", IntegralLeadership Review. Volume VI, No. 3

[21] Amram, Y., \& Dryer, C. (2007). The development and preliminary validation of the Integrated Spiritual Intelligence Scale. ISIS, 193-272.

[22] King, D. (2008). Rethinking claims of spiritual intelligence: A definition, model, and measure (M.Sc.). Trent University (Canada), Canada.

[23] Sinetar, M. (2000). Spiritual intelligence: What we can learn from the early awakening child. Orbis Books.

[24] Jung, C. G. (1973). Synchronicity: An acausal connecting principle. Princeton, NJ: Princeton University Press. (Original work published 1960)

[25] Sisk, D. A., \& Torrance, E. P. (2001). Spiritual intelligence: Developing higher consciousness. New York: Creative Education Foundation Press.

[26] Dabrowski, K. (1967). Personality-shaping through positive disintegration. Boston: Little Brown.

[27] Eriksson, G., \& Wallace, B. (Eds.). (2006). Diversity in gifted education: International perspectives on global issues. Routledge.

[28] Rogers, C. R. (1980). A way of being. Boston: Houghton Mifflin Company

[29] Rogers, C. R. (1959). A theory of therapy, personality, and interpersonal relationships: As developed in the client-centered framework (Vol. 3, pp. 184-256). New York: McGrawHill.

[30] Maslow, A. H. (1954). Motivation and personality. New York: Harper \& Brothers:New York, USA

[31] Wilber, K. (1999). One taste. Random House.

[32] Vaughan, F. E. (1979). Awakening intuition. Anchor.

[33] Fowler, J. (1995). Stages of faith: The psychology of human development and the quest for meaning. San Francisco: HarperSanFrancisco

[34] King, D. B., \& DeCicco, T. L. (2009). A viable model and self-report measure of spiritual intelligence. International journal of transpersonal studies, 28(1), 8. 
[35] Meddin, J. R. (1998). Dimensions of spiritual meaning and well-being in the lives of ten older Australians. The International Journal of Aging and Human Development, 47(3), 163-175. https://doi.org/10.2190/1lxa-k5tn-bgy4-faxv

[36] Maslow, A. H. (1971). The farther reaches of human nature.New York, NY: Viking Press

[37] Maslow, A. H. (1964). Religions, values, and peak-experiences (Vol. 35). Columbus: Ohio State University Press.

[38] Cahn, B. R., \& Polich, J. (2006). Meditation states and traits: EEG, ERP, and neuroimaging studies. Psychological bulletin, 132(2), 180. https://doi.org/10.1037/0033$\underline{2909.132 .2 .180}$

[39] Amram, Y. (2007). The seven dimensions of spiritual intelligence: An ecumenical, grounded theory. In 115th annual conference of the American psychological association, San Francisco, CA (pp. 17-20). https://doi.org/10.1037/e706302007-001

[40] Amram, Y., \& Dryer, C. D. (2008). The development and integrated spiritual intelligence scale (ISIS). Palo Alto, CA: Institute of Transpersonal Psychology Working, Available on WWW. geocities. com

[41] Halama, P., \& Strizenec, M. (2004). Spiritual, existential or both? Theoretical considerations on the nature of "higher intelligences. Studia Psychologica, 46(3), 239-253

[42] Wigglesworth, C. (2014). SQ21: The twenty-one skills of spiritual intelligence. SelectBooks, Inc

[43] Isaacs, A. Physical Intelligence and Will.

[44] Drigas, A., \& Karyotaki, M. (2018). Mindfulness Training \& Assessment and Intelligence. International Journal of Recent Contributions from Engineering, Science \& IT (iJES), 6(3), 70-85. https://doi.org/10.3991/ijes.v6i3.9248

[45] Saotome, Mistsugi. 1993. Aikido and the Harmony of Nature. Shambhala, Boston

[46] Taylor, J. B. (2009). My stroke of insight. Hachette UK.

[47] Spearman, C. (1927). The abilities of man (Vol. 89). New York: Macmillan

[48] Mayer, J. D., \& Salovey, P. (1997). What is emotional intelligence? In P. Salovey, \& D. J. Sluyter (Eds.), Emotional development and emotional intelligence: Educational implications (pp. 3-31). New York, NY. Basic Books. https://doi.org/10.1037/t05047-000

[49] Boyatzis, R. E., Goleman, D., \& Rhee, K. (2000). Clustering competence in emotional intelligence: Insights from the Emotional Competence Inventory (ECI). Handbook of emotional intelligence, 99(6), 343-362.

[50] Drigas, A., \& Papoutsi, C. (2018). A new layered model on emotional intelligence. Behavioral Sciences, 8(5), 45.

[51] Fuller, R. C. (2008). Spirituality in the flesh: Bodily sources of religious experiences. Oxford University Press.

[52] Rogers, C. R. (1951). Client-Centered therapy. Boston: Houghton Mifflin Company

[53] Wilber, K. (2014). The Atman project: A transpersonal view of human development. Quest Books.

[54] Daniels, M. (2001). On transcendence in transpersonal psychology. Transpersonal Psychology Review, 5(2), 3-11.

[55] Lajoie, D. H., \& Shapiro, S. I. (1992). Definitions of transpersonal psychology: The first twenty-three years. The Journal of Transpersonal Psychology, 24(1), 79.

[56] Walsh, R. \& Vaughan, F. (1993). On transpersonal definitions. Journal of Transpersonal Psychology, 25(2), 199-207.

[57] Haynes, C. (2016). Identity, transcendence and the true self: Insights from psychology and contemplative spirituality. HTS Theological Studies, 72(4), 1-9. https://doi.org/10.4 102/hts.v72i4.3455

[58] Frankl, V. E. (1985). Man's search for meaning. Simon and Schuster. 
[59] Piedmont, R. L. (1999). Does spirituality represent the sixth factor of personality? Spiritual transcendence and the five-factor model. Journal of personality, 67(6), 985-1013. https://doi.org/10.1111/1467-6494.00080

[60] Garcia-Romeu, A., Himelstein, S. P., \& Kaminker, J. (2015). Self-transcendent experience: A grounded theory study. Qualitative Research, 15(5), 633-654. https://doi.org/10.117 $\underline{7 / 1468794114550679}$

[61] Feuerstein, G. (2018). On the Nature of Consciousness and Reality: An Overview of Jean Gebser's Thoughts on Consciousness. Journal of Conscious Evolution, 1(1), 11.

[62] Koltko-Rivera, M. E. (2006). Rediscovering the later version of Maslow's hierarchy of needs: Self-transcendence and opportunities for theory, research, and unification. Review of general psychology, 10(4), 302-317. https://doi.org/10.1037/1089-2680.10.4.302

[63] Vaughan, F., \& Walsh, R. (1993). The art of transcendence: An introduction to common elements of transpersonal practices. The Journal of Transpersonal Psychology, 25(1), 1-9.

[64] Karyotaki, M., Drigas, A., \& Skianis, C. (2017). Attentional Control and other Executive Functions. International Journal of Emerging Technologies in Learning, 12(3).

[65] Health, D. (1983). The maturing person. In Walsh, R. \& Shapiro, D. J. (Eds.), Beyond health and normality: Explorations of exceptional psychological well-being (pp, 152-205). New York: Van Nostrand Reinhold

[66] Wilber, K. (2016). Integral meditation: Mindfulness as a way to grow up, wake up, and show up in your life. Shambhala Publications.

[67] Biela, A. (2014). Paradigm of Unity as a Prospect for Research and Treatment in Psychology. Journal for Perspectives of Economic Political and Social Integration, 19(1-2), 207227. https://doi.org/10.2478/v10241-012-0018-2

[68] Mehta, B. (2017). Self-Knowledge as Non-Dual Awareness: A Comparative Study of Plotinus and Indian Advaita Philosophy. The International Journal of the Platonic Tradition, 11(2), 117-148. https://doi.org/10.1163/18725473-12341375

[69] Stavros, B. J. (2014). Empedocles and Neurosciences. ENCEPHALOS, 51, 66-78.

[70] Eneyo, M. B. (2019). Philosophy of unity: Love as an ultimate unifier. Xlibris Corporation.

[71] Amir Kiaei, Yalda. (2014).The Relationship between Metacognition, Self-Actualization, and Well-Being among University Students: Reviving Self-Actualization as the Purpose of Education.FIU Electronic Theses and Dissertations. Paper 1367.Retrieved from http://digitalcommons.fiu.edu/etd/1367. https://doi.org/10.25148/etd.fi14040889

[72] Singh, M., \& Bali, A. Metacognition and Spiritualism: Development of Reflective Mind and a way to live Peaceful Life. RESEARCHERS ORGANIZATION BILASPUR (CG), 82.

[73] Vago, D. R., \& David, S. A. (2012). Self-awareness, self-regulation, and selftranscendence (S-ART): a framework for understanding the neurobiological mechanisms of mindfulness. Frontiers in human neuroscience, 6, 296. https://doi.org/10.33 $\underline{\text { 89/fnhum.2012.00296 }}$

[74] Santoso, D. (2016). Improving the Students' Spiritual Intelligence in English Writing through Whole Brain Learning. English Language Teaching, 9(4), 230-238. https://doi.org/10.5539/elt.v9n4p230

[75] Selman, V., Selman, R. C., Selman, J., \& Selman, E. (2005). Spiritual-intelligence/quotient. College Teaching Methods \& Styles Journal (CTMS), 1(3), 23-30. https://doi.org/10.19030/ctms.v1i3.5236

[76] Tart, C. T. (1986). Consciousness, altered states, and worlds of experience. Journal of Transpersonal Psychology, 18(2), 159-170.

[77] Wilber, K. (1979). A developmental view of consciousness. Journal of Transpersonal Psychology, 11(1), 1-21. 
[78] Brazdau, O. (2015). The Consciousness Quotient: Construct Development and Content Validity Research. Procedia-Social and Behavioral Sciences, 187, 244-249. https://doi.org/10.1016/j.sbspro.2015.03.046

[79] Ahuja, S. (2011). A Correlational Analysis of Physical, Mental, Emotional, Spiritual, Social and Self-Consciousness.

[80] Kuhl J. \& Fuhrmann A. (2008) "Decomposing self-regulation and selfcontrol: the volitional component inventory," in Motivation and Self-Regulation Across the Life Span, J. Heckhausen and C. S. Dweck, Eds., pp. 15-45, Cambridge University Press, Cambridge, UK, 2nd edition, 2008. https://doi.org/10.1017/cbo9780511527869.003

[81] Adams, A. (2018). Educating for Conscious Evolution. Journal of Conscious Evolution, 3(3), 8 .

[82] Prabhu, H. A., \& Bhat, P. S. (2013). Mind and consciousness in yoga-Vedanta: A comparative analysis with western psychological concepts. Indian journal of psychiatry, 55(Suppl 2), S182. https://doi.org/10.4103/0019-5545.105524

[83] Purushothaman, A., \& Kumaran, S. (2014). A vedantic study of" cosmic consciousness"Brahmam. Journal of Indian Culture and Civilization, 1, 1-27.

\section{Authors}

Athanasios Drigas is a Research Director at N.C.S.R. 'Demokritos', Institute of Informatics and Telecommunications - Net Media Lab \& Mind-Brain R\&D, Agia Paraskevi, 153 10, Athens, Greece (e-mail: dr@iit.demokritos.gr).

Eleni Mitsea is with Institute of Informatics and Telecommunications - Net Media Lab \& Mind-Brain R\&D, Agia Paraskevi, 153 10, Athens, Greece (e-mail: e.mitsea@gmail.com).

Article submitted 2019-11-25. Resubmitted 2020-02-19. Final acceptance 2020-02-19. Final version published as submitted by the authors. 